\title{
OPEN Persistent symptoms and lab abnormalities in patients who recovered from COVID-19
}

\author{
Julian Varghese ${ }^{1 \bowtie}$, Sarah Sandmann ${ }^{1}$, Kevin Ochs ${ }^{2}$, Inga-Marie Schrempf ${ }^{2}$, \\ Christopher Frömmel ${ }^{2}$, Martin Dugas ${ }^{1,3}$, Hartmut H. Schmidt ${ }^{2,4}$, Richard Vollenberg ${ }^{2,4}$ \& \\ Phil-Robin Tepasse ${ }^{2,4}$
}

With increasing numbers of patients recovering from COVID-19, there is increasing evidence for persistent symptoms and the need for follow-up studies. This retrospective study included patients without comorbidities, who recovered from COVID-19 and attended an outpatient clinic at a university hospital for follow-up care and potential convalescent plasma donation. Network analysis was applied to visualize symptom combinations and persistent symptoms. Comprehensive lab-testing was ascertained at each follow-up to analyze differences regarding patients with vs without persistent symptoms. 116 patients were included, age range was 18-69 years (median: 41) with follow-ups ranging from 22 to 102 days. The three most frequent persistent symptoms were Fatigue (54\%), Dyspnea (29\%) and Anosmia (25\%). Lymphopenia was present in 13 of 112 (12\%) cases. Five of 35 cases (14\%) had Lymphopenia in the later follow-up range of 80-102 days. Serum IgA concentration was the only lab parameter with significant difference between patients with vs without persistent symptoms with reduced serum IgA concentrations in the patient cohort of persistent symptoms $(p=0.0219)$. Moreover, subgroup analyses showed that patients with lymphopenia experienced more frequently persistent symptoms. In conclusion, lymphopenia persisted in a noticeable percentage of recovered patients. Patients with persistent symptoms had significantly lower serum IgA levels. Furthermore, our data provides evidence that lymphopenia is associated with persistence of COVID-19 symptoms.

COVID-19 (Coronavirus disease 2019) disease has spread as pandemic, causing more than 1 million global deaths as of November $2020^{1}$ and shows a multifaceted condition with various symptoms due to various organ manifestations $s^{2-5}$. There is also an increasing number of recovered patient cases, which can provide new essential insights on the disease course. While the clinical feature characterization of COVID-19 is well-studied for the disease onset ${ }^{3,6-8}$, follow-up information on persistent symptoms and lab findings is scarce ${ }^{9}$. In addition, most work on symptomatology has not studied clusters of co-occurring symptoms in a single patient. Indeed, a systematic review by Struyf et al. ${ }^{10}$ found that combinations of symptoms were not assessed in a single study. However, as newer publications are quickly emerging, we found one study on frequent symptoms clusters ${ }^{11}$.

This work is a retrospective evaluation of university hospital data of patients, who recovered from COVID-19 and were screened for convalescent plasma donation eligibility. Since patients with comorbidities were excluded, our study provides insights on the healthy population, in which COVID-19 disease course is not well-studied.

Standardized symptom characterization report forms and all free-text elements of discharge letters were added for analyses. This facilitates the extraction of infection-related symptoms, which are not explicitly listed in structured forms. Moreover, details on persistent symptoms and duration to symptom-free phase could be sufficiently extracted in almost all of the cases. As a simple, but highly expressive visualization technique, network analysis illustrates clusters of symptoms and persistent symptoms in one graph-based plot. Blood sampling enabled comprehensive lab-data including whole blood analysis, serum chemistry and immunoglobulins. The combination of detailed symptom duration documentation and raw lab-data enables deep analyses of lab differences-also within the physiological range-in patients with versus without persistent symptoms. By doing this,

${ }^{1}$ Institute of Medical Informatics, University of Münster, Ibert-Schweitzer-Campus 1/Gebäude A11, 48149 Münster, Germany. ${ }^{2}$ Department of Medicine B, Gastroenterology and Hepatology, University Hospital Münster, Münster, Germany. ${ }^{3}$ Institute of Medical Informatics, University Hospital Heidelberg, Heidelberg, Germany. ${ }^{4}$ These authors contributed equally: Richard Vollenberg and Phil-Robin Tepasse. ${ }^{\circledR}$ email: julian.varghese@uni-muenster.de 
Münsterland Region, Germany

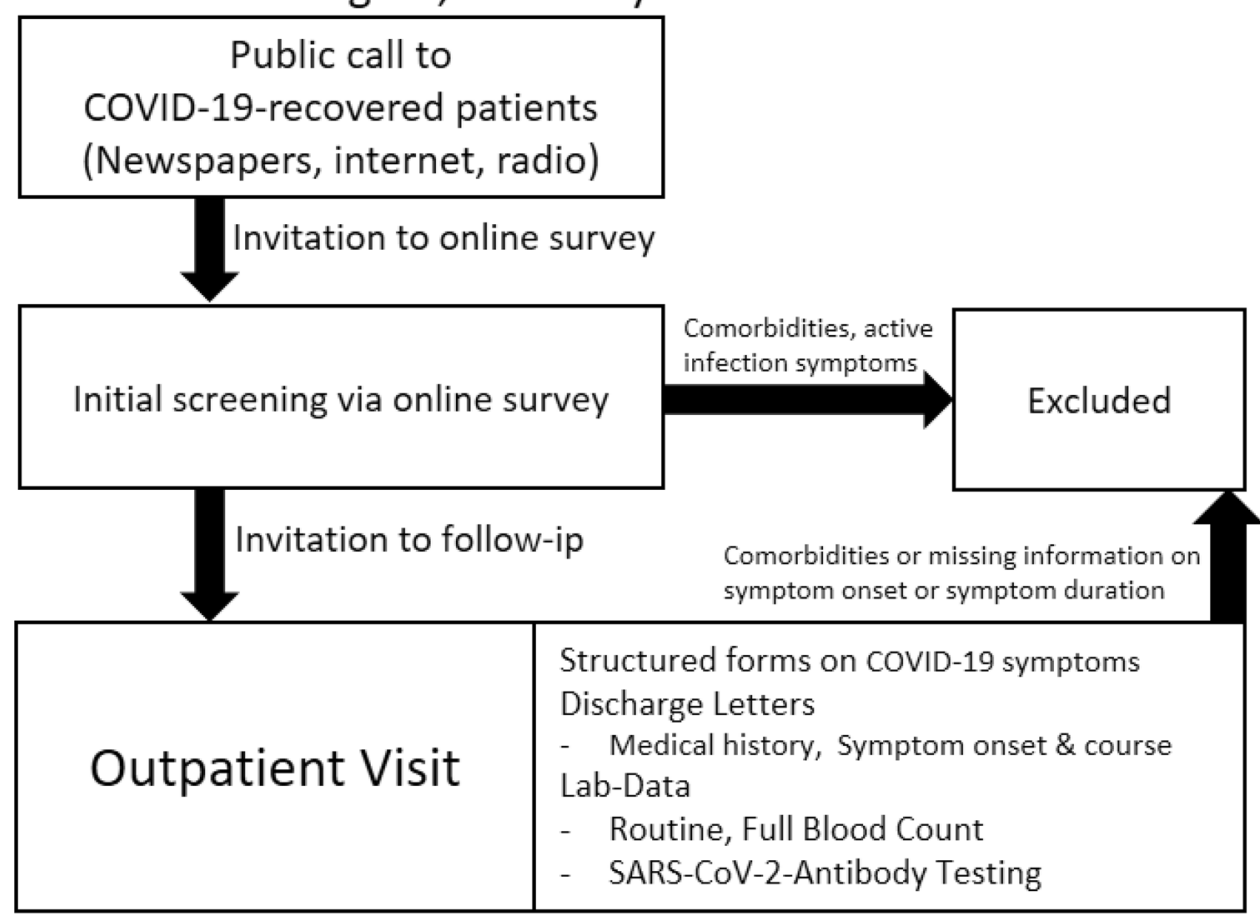

\section{University Hospital Münster}

Figure 1. Inclusion of study population.

the study evaluated lab abnormalities including but not limited to general infection parameters, in particular lymphopenia, being discussed as a hot-topic and prognostic factor in disease onset ${ }^{12-14}$.

\section{Methods}

Setting. This is a single center retrospective study in the University Hospital of Münster in Germany. Patients who recovered after confirmed diagnosis of COVID-19 were invited upon an open public call in the Münsterland region of Germany. The primary purpose of this call was to find eligible patients for a plasma donation study ${ }^{15}$. The ethical board of the University of Münster and the physician's chamber of Westphalia-Lippe approved the study protocol (Reference number: AZ 2020-220-f-S) ${ }^{15}$. All included patients provided informed consent for scientific analyses. All methods were performed in accordance with the Declaration of Helsinki and with the relevant guidelines and regulations.

Figure 1 illustrates the screening process and data collection. Patients with comorbidities or active infection symptoms within the last four weeks were excluded. Final assessment was carried out via outpatient visit at the University Hospital with medical history taking and lab testing. From this stage, further patients were excluded from this study if comorbidities were deemed to be existing or if there was missing information on symptom onset or symptom duration.

Data extraction. Symptoms were obtained from structured clinical forms and discharge letters. Attending physicians were required to document onset of symptoms, duration and persistence of symptoms. Symptoms were defined to be persistent if they endured for at least 28 days from the onset. Single symptoms and possible combinations were extracted, but not the duration of each single symptom as this was not documented consistently.

Lab values and corresponding reference ranges were queried from the laboratory information system. Discharge letters were examined by a physician with infection-related symptoms being mapped to medical concepts of the standardized forms or added as new symptoms. Symptoms being highly similar were summarized to one medical concept.

Data analysis. Network analysis of symptoms was conducted using the R-package igraph $1.2^{16}$ to show frequency and graph-based co-occurrence of onset-symptoms and persistent symptoms. Descriptive statistics were calculated for patient cohort characteristics. Age and gender were compared in the two cohorts with vs without persistent symptoms using 2-tailed t-tests $(\mathrm{alpha}=0.05)$ and Fisher's exact test, respectively. Lab data was summarized with descriptive statistics and proportions below and above reference ranges. In addition, lab values were compared between the two cohorts using 2-tailed t-tests (alpha $=0.05$; adjustment for multiple testing using Bonferroni correction). Calculations were conducted in $\mathrm{R}$, version 4.03 . 


\begin{tabular}{|l|l|}
\hline Patient Characteristics (n= 116) & Value \\
\hline Age, median (IQR), y & $41(31-55)$ \\
\hline Female sex, no. (\%) & $17(15 \%)$ \\
\hline Follow-up time, median (IQR), d & $66(44-82)$ \\
\hline Positive SARS-CoV2- antibody testing, no. (\%) & $70(80 \%)$ \\
\hline Requiring Hospital admission no. (\%) & $10(9 \%)$ \\
\hline With Persistent Symptoms, No. (\%) & $21 \%)$ \\
\hline - Age, median (IQR), y & $34-57)$ \\
\hline - Female sex, No. (\%) & $5(21 \%)$ \\
\hline Without Persistent Symptoms & $79 \%)$ \\
\hline - Age, median (IQR), y & $30-54)$ \\
\hline - Female sex, No. (\%) & $12(13 \%)$ \\
\hline
\end{tabular}

Table 1. Demographic and Clinical Characteristics of patients $(n=116)$.

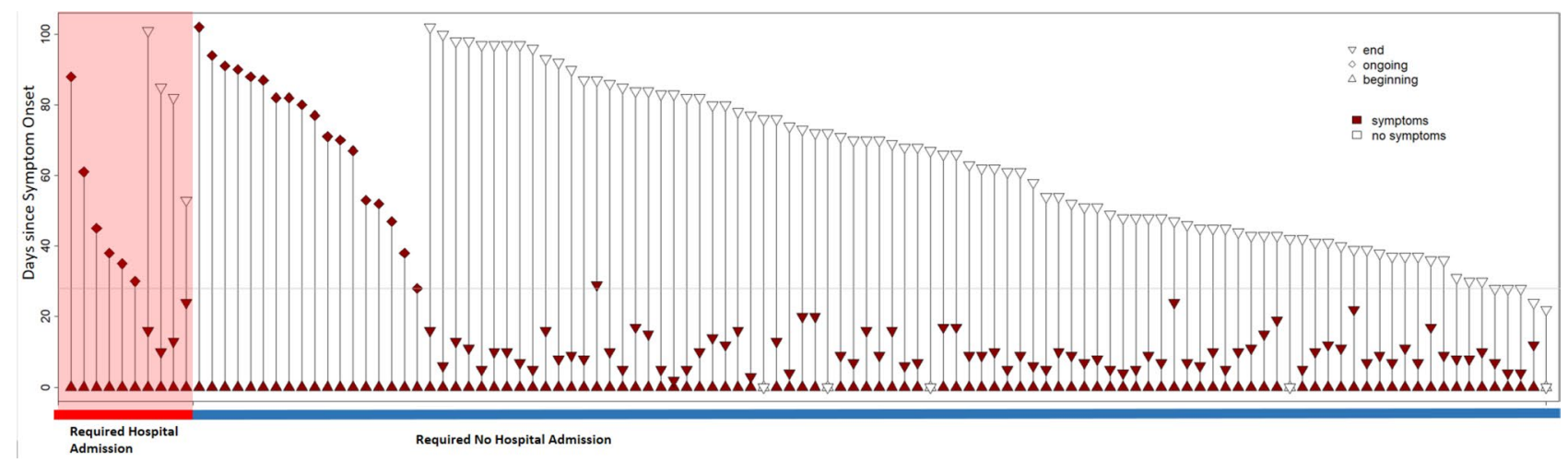

Figure 2. Follow-up day and symptom duration for each patient. Grey horizontal line represents threshold for persistent symptoms (28 days). Five patients were asymptomatic (symptom start and end at day 0 ).

\section{Results}

Patient cohort. After participation in the online-survey, 122 patients were screened eligible and attended the outpatient clinic for final assessment during June and September 2020. Six patients were excluded due to insufficient information on symptom duration or comorbidities $(n=116)$. The age range was $18-69$ years, with median of 41 years (IQR 30-54). Table 1 summarizes further cohort details. Comparing the two patient cohorts with $(n=92)$ vs without persistent symptoms $(n=24)$, no significant difference can be observed regarding age ( $\mathrm{t}$-test, $p=0.2497$ ) and gender (Fisher's exact test, $p=0.3415$ ). Follow-up ranged from 22 to 102 days. Figure 2 illustrates follow-up times from symptom onset and symptom durations of all patients.

Symptom analyses. After extraction of infection-related concepts in the discharge letters, the concept "Reduced Physical Resilience" was subsumed to "Fatigue". Myalgia and signs of arthralgia were subsumed to Myalgia. Tinnitus was added as new symptom as it did not occur in the structured standard. Figure 3 shows the network analysis of onset and persistent symptoms. The five most frequent onset symptoms were Cough (50\%), Anosmia (47\%), Fatigue (45\%), Fever (42\%), Myalgia (28\%) and Headache (28\%). Among patients with persistent symptoms $(\mathrm{n}=24)$, the three most frequent persistent symptoms were Fatigue $(\mathrm{n}=13,54 \%$, $\min =28 \mathrm{~d}$, $\max \geq 94 \mathrm{~d})$, Dyspnea $(29 \%, \min =25 \mathrm{~d}, \max \geq 102 \mathrm{~d})$ and Anosmia $(25 \%, \min =41 \mathrm{~d}, \max \geq 91 \mathrm{~d})$. A web-based platform was established to upload anonymous symptoms data to generate and reproduce network analysis based on own or other cohorts ${ }^{17}$.

Lab abnormalities. Table 2 summarizes the outcome of all lab measurements, which were available in more than $95 \%$ of all patient cases. Increased values above the reference range can be observed in more than $10 \%$ of patients for Creatine Kinase, Glucose, GOT, GPT, Potassium, LDH and Platelets count. Decreased values can be observed for eGFR and absolute Lymphocyte count. Lymphopenia was present in 13 of 112 (12\%) cases. These cases had results below the lab-specific reference range of $1.26-3.35 \times 10^{9} / \mathrm{L}$ (follow-up range: $45-102 \mathrm{~d}$, median: 70d). Figure 4 details lymphocyte count over all follow-up times for all cases.

The subgroup of 13 lymphopenic cases had 4 patients (31\%) with persistent symptoms and 9 patients without persistent symptoms. The remaining 99 cases with normal Lymphocyte count had 19 patients (19\%) with persistent symptoms and 80 patients without. 


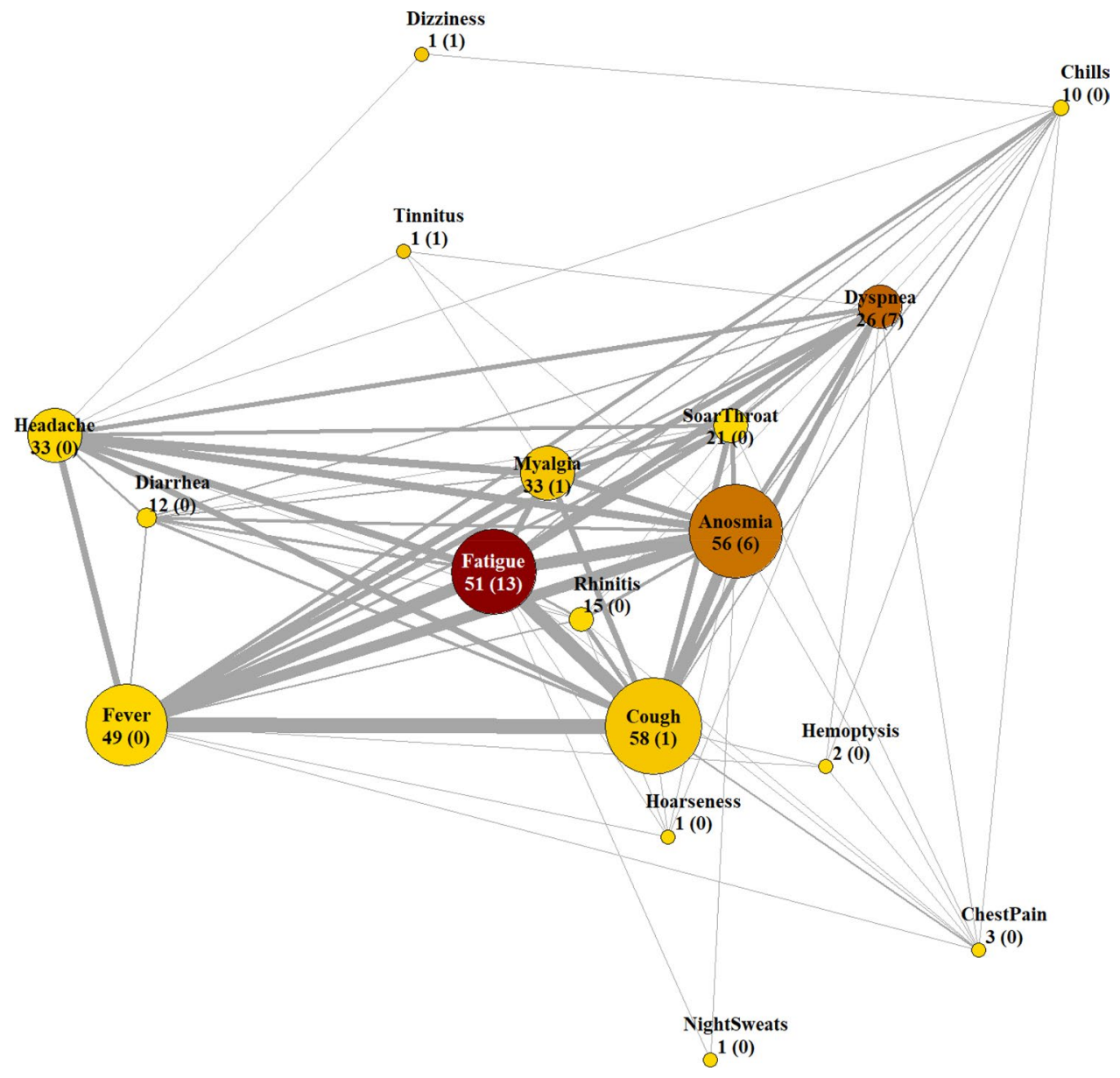

Figure 3. Network analyses of symptom nodes. Node size and node number correspond to the number of patients having that onset symptom. The number in parentheses corresponds to persistent symptoms, which is also indicated by the redness of the symptom node. Thickness of grey edges corresponds co-occurrence of onset symptoms.

In the late follow-up range of 80-102 days, lymphopenia was still present in 5 of 35 cases (14\%, follow-up range: $82-102 \mathrm{~d}$, median: $83 \mathrm{~d}$ ). The subgroup of 5 lymphopenic cases had 2 patients with persistent symptoms and 3 patients without persistent symptoms. The remaining 30 cases with normal Lymphocyte count had 8 patients (19\%) with persistent symptoms and 22 patients without.

After adjusting for multiple testing for all lab measurements, IgA was the only parameter - also among other Immunoglobulins - that remained significantly different between patients with and without persistent symptoms (see Table 2). It was significantly reduced in patients with persistent symptoms $(p=0.0219)$.

\section{Discussion}

This study found that a noticeable amount of COVID-19-recovered patients still had $(\mathrm{n}=24,21 \%)$ persistent symptoms. In $13 \%$ of the cases they persisted for 60 days and longer. The three most frequent ones were Fatigue, Anosmia and Dyspnea. These are also listed as long-term symptoms by the National Institute Health and Care Excellence $^{18}$ and CDC as information for health care providers ${ }^{19}$. While Fatigue and Dyspnea are explainable as general infection symptoms and manifestation of the lungs, Anosmia is reported to be a frequent symptom suspecting other pathogenesis than only nasal obstruction ${ }^{20}$. There is growing evidence that the SARS-CoV-2 initiates key cellular processes in the olfactory epithelium ${ }^{21}$.

The results on persistent symptoms are similar to existing follow-up studies: A post-acute- follow-up study in Italy by Carfi et al. ${ }^{9}$ evaluated Fatigue and Dyspnea but not Anosmia as persistent symptoms (mean followup 60.3 days). A follow-up study by Carvalho-Schneider et al..$^{22}$ reported the identical set of our most common persistent symptoms (follow-up at day 30 and 60, non-critical COVID-19 patients). Comparing to a study by Garrigues et al. ${ }^{23}$ with a mean of 110.9 days, Fatigue and Dyspnea were the most common, followed by Loss of Memory. These findings support a common symptom set regardless of patient case severity. However, as with many symptom-related infection studies, signs of neuro-degenerative or mental health disorders could be under-reported. They were not documented in our study as they were not reported by the patients and not part of the structured forms. 


\begin{tabular}{|c|c|c|c|c|c|c|c|}
\hline \multirow[b]{2}{*}{ Lab-Value (Unit) } & \multicolumn{3}{|l|}{ All } & \multicolumn{4}{|c|}{ Comparison PS vs N-PS } \\
\hline & Normal range $\%$ & Below\% & Above \% & PS, mean (SD) & N-PS, mean (SD) & $p$-value & Adjusted $p$-value \\
\hline Albumin $(\mathrm{g} / \mathrm{dL})$ & 98,23 & 0,00 & 1,77 & $4.54(0.31)$ & $4.59(0.22)$ & 0,4709 & 1 \\
\hline Alkal. phosphatase(U/L) & 98,23 & 1,77 & 0,00 & $62.87(15.72)$ & $62.83(15.91)$ & 0,9922 & 1 \\
\hline Antithrombin (\%) & 99,11 & 0,89 & 0,00 & $98.57(7.55)$ & $97.69(8.68)$ & 0,6321 & 1 \\
\hline $\begin{array}{l}\text { Basophilic abs. (1000/ } \\
\mu \mathrm{L})\end{array}$ & 93,75 & 0,89 & 5,36 & $0.04(0.01)$ & $0.04(0.02)$ & 0,1819 & 1 \\
\hline Basophilic rel. (\%) & 94,64 & 0,89 & 4,46 & $0.62(0.29)$ & $0.74(0.34)$ & 0,1079 & 1 \\
\hline Bilirubin total $(\mathrm{mg} / \mathrm{dL})$ & 95,58 & 0,00 & 4,42 & $0.73(0.59)$ & $0.56(0.24)$ & 0,1788 & 1 \\
\hline $\mathrm{CRP}(\mathrm{mg} / \mathrm{dL})$ & 94,69 & 0,00 & 5,31 & $0.41(0.04)$ & $0.41(0.06)$ & 0,7412 & 1 \\
\hline Creatinine $(\mathrm{mg} / \mathrm{dL})$ & 100,00 & 0,00 & 0,00 & $0.91(0.16)$ & $0.92(0.14)$ & 0,7813 & 1 \\
\hline Creatine kinase (U/L) & 66,37 & 0,00 & 33,63 & $121.78(64.42)$ & $173.76(139.93)$ & 0,0110 & 0,5598 \\
\hline $\begin{array}{l}\text { eGFR - CKD EPI (mL/ } \\
\text { min) }\end{array}$ & 75,22 & 24,78 & 0,00 & $93.57(4.91)$ & $93.82(5)$ & 0,8246 & 1 \\
\hline Total Protein $(\mathrm{g} / \mathrm{dL})$ & 97,35 & 1,77 & 0,88 & $7.38(0.34)$ & $7.38(0.36)$ & 0,9302 & 1 \\
\hline $\begin{array}{l}\text { Eosinoph. abs. (1000/ } \\
\mu \mathrm{L})\end{array}$ & 94,64 & 2,68 & 2,68 & $0.14(0.08)$ & $0.15(0.12)$ & 0,5812 & 1 \\
\hline Eosinoph. relative (\%) & 95,54 & 1,79 & 2,68 & $2.49(1.56)$ & $2.68(2.02)$ & 0,6246 & 1 \\
\hline $\begin{array}{l}\text { Erythrocytes/RBC } \\
(\text { Mio. } / \mu \mathrm{L})\end{array}$ & 87,50 & 2,68 & 9,82 & $4.92(0.45)$ & $5(0.41)$ & 0,4013 & 1 \\
\hline Ferritin $(\mu \mathrm{g} / \mathrm{L})$ & 83,19 & 7,08 & 9,73 & $191.48(185.22)$ & $177.03(140.19)$ & 0,7294 & 1 \\
\hline Fibrinogen $(\mathrm{mg} / \mathrm{dL})$ & 95,58 & 0,88 & 3,54 & $311.65(78.52)$ & $294.34(48.33)$ & 0,3220 & 1 \\
\hline Gamma-GT (U/L) & 93,81 & 0,00 & 6,19 & $33.04(25.52)$ & $30.23(22.04)$ & 0,6319 & 1 \\
\hline Glucose (mg/dL) & 88,60 & 0,88 & 10,53 & $90(17.68)$ & $90.85(21.71)$ & 0,8461 & 1 \\
\hline GOT/AST. (U/L) & 81,42 & 0,00 & 18,58 & $28.09(5.42)$ & $29.1(8.7)$ & 0,4892 & 1 \\
\hline GPT/ALT. (U/L) & 78,76 & 0,00 & 21,24 & $30.3(18.04)$ & $31.02(13.38)$ & 0,8595 & 1 \\
\hline Hematokrit (\%) & 93,75 & 6,25 & 0,00 & $42.95(3.22)$ & $43.1(2.83)$ & 0,8372 & 1 \\
\hline Hemoglobin $(\mathrm{g} / \mathrm{dL})$ & 93,75 & 5,36 & 0,89 & $14.53(1.23)$ & $14.64(1.1)$ & 0,6949 & 1 \\
\hline $\operatorname{IgA}(\mathrm{mg} / \mathrm{dL})$ & 92,98 & 1,75 & 5,26 & 172.17 (57.95) & 231.29 (97.25) & 0,0004 & 0,0219 \\
\hline $\operatorname{IgG}(\mathrm{mg} / \mathrm{dL})$ & 98,25 & 0,00 & 1,75 & $1143.2(185.03)$ & 1113.07 (193.5) & 0,4937 & 1 \\
\hline $\operatorname{IgM}(\mathrm{mg} / \mathrm{dL})$ & 87,72 & 6,14 & 6,14 & $146.26(192.42)$ & $102.78(73.43)$ & 0,2979 & 1 \\
\hline INR (ratio) & 100,00 & 0,00 & 0,00 & $0.99(0.05)$ & $0.98(0.05)$ & 0,7382 & 1 \\
\hline $\begin{array}{l}\text { Immat. Granulocytes } \\
(1000 / \mu \mathrm{L})\end{array}$ & 99,11 & 0,00 & 0,89 & $0.02(0.01)$ & $0.02(0.01)$ & 0,2752 & 1 \\
\hline Interleukin.6 (pg/mL) & 99,12 & 0,00 & 0,88 & $2.09(0.52)$ & $2.15(1.1)$ & 0,6824 & 1 \\
\hline $\mathrm{LDH}(\mathrm{U} / \mathrm{L})$ & 68,14 & 0,88 & 30,97 & $226.74(46.82)$ & $210.77(39.87)$ & 0,1431 & 1 \\
\hline Leukocytes (Tsd. $/ \mu \mathrm{L})$ & 92,86 & 7,14 & 0,00 & $6.11(1.36)$ & $5.77(1.32)$ & 0,2826 & 1 \\
\hline Lipase (U/L) & 93,81 & 0,00 & 6,19 & $40.13(12.79)$ & $35.32(14.33)$ & 0,1252 & 1 \\
\hline $\begin{array}{l}\text { Lymphocytes abs. } \\
(1000 / \mu \mathrm{L})\end{array}$ & 86,61 & 11,61 & 1,79 & $1.8(0.57)$ & $1.81(0.54)$ & 0,9501 & 1 \\
\hline $\begin{array}{l}\text { Lymphocytes relative } \\
(\%)\end{array}$ & 91,07 & 6,25 & 2,68 & $29.62(7.16)$ & $31.77(7.34)$ & 0,2084 & 1 \\
\hline $\mathrm{MCH}(\mathrm{pg})$ & 91,96 & 6,25 & 1,79 & $29.61(1.66)$ & $29.31(1.59)$ & 0,4460 & 1 \\
\hline MCHC (g/dL) & 83,93 & 3,57 & 12,50 & $33.82(1.01)$ & $33.96(0.93)$ & 0,5573 & 1 \\
\hline MCV (fL) & 91,07 & 8,93 & 0,00 & $87.58(3.85)$ & $86.32(4.07)$ & 0,1771 & 1 \\
\hline $\begin{array}{l}\text { Monocytes abs. (1000/ } \\
\mu \mathrm{L})\end{array}$ & 95,54 & 2,68 & 1,79 & $0.53(0.18)$ & $0.51(0.14)$ & 0,5755 & 1 \\
\hline Monozyten relative (\%) & 97,32 & 1,79 & 0,89 & $8.89(2.54)$ & $8.97(1.91)$ & 0,8864 & 1 \\
\hline Sodium $(\mathrm{mmol} / \mathrm{L})$ & 100,00 & 0,00 & 0,00 & $140.74(1.68)$ & $140.74(1.68)$ & 0,7060 & 1 \\
\hline $\begin{array}{l}\text { Neutrophilic abs. (1000/ } \\
\mu \mathrm{L})\end{array}$ & 95,54 & 4,46 & 0,00 & $3.6(1.06)$ & $3.26(1.05)$ & 0,1686 & 1 \\
\hline $\begin{array}{l}\text { Neutrophilic relative } \\
(\%)\end{array}$ & 93,75 & 3,57 & 2,68 & $58.4(6.65)$ & $55.84(8.55)$ & 0,1309 & 1 \\
\hline $\begin{array}{l}\text { Part. Thrombopl. } \\
\text { Time (s) }\end{array}$ & 91,15 & 0,88 & 7,96 & $34.13(2.6)$ & $34.19(3.01)$ & 0,9263 & 1 \\
\hline Platelets $(1000 / \mu \mathrm{L})$ & 83,04 & 6,25 & 10,71 & $265.3(71.97)$ & $236.55(48.63)$ & 0,0809 & 1 \\
\hline Potassium $(\mathrm{mmol} / \mathrm{L})$ & 74,34 & 4,42 & 21,24 & $4.3(0.67)$ & $4.35(0.62)$ & 0,7593 & 1 \\
\hline Procalcitonin $(\mathrm{ng} / \mathrm{mL})$ & 100,00 & 0,00 & 0,00 & $0.05(0.02)$ & $0.05(0.03)$ & 0,4861 & 1 \\
\hline $\begin{array}{l}\text { Pseudocholinesterase } \\
(\mathrm{U} / \mathrm{L})\end{array}$ & 100,00 & 0,00 & 0,00 & $8493.1(1884.5)$ & $8642.5(1476.9)$ & 0,7264 & 1 \\
\hline Sodium $(\mathrm{mmol} / \mathrm{L})$ & 100,00 & 0,00 & 0,00 & $140.74(1.68)$ & $140.74(1.68)$ & 0,7060 & 1 \\
\hline Thrombin time (s) & 100,00 & 0,00 & 0,00 & $17.52(0.79)$ & $17.19(0.7)$ & 0,0748 & 1 \\
\hline Continued & & & & & & & \\
\hline
\end{tabular}




\begin{tabular}{|l|l|l|l|l|l|l|l|}
\hline \multirow{2}{*}{ Lab-Value $($ Unit) } & \multicolumn{4}{|l|}{ All } & Comparison PS vs N-PS \\
\cline { 2 - 8 } & Normal range $\%$ & Below\% & Above $\%$ & PS, mean $(\mathrm{SD})$ & N-PS, mean $(\mathrm{SD})$ & $\boldsymbol{p}$-value & Adjusted $\boldsymbol{p}$-value \\
\hline TSH $(\mu \mathrm{U} / \mathrm{mL})$ & 100,00 & 0,00 & 0,00 & $1.4(0.69)$ & $1.5(0.63)$ & 0,5134 & 1 \\
\hline Urea $(\mathrm{mg} / \mathrm{dL})$ & 99,12 & 0,00 & 0,88 & $13.43(3.3)$ & $14.07(3.45)$ & 0,4223 & 1 \\
\hline
\end{tabular}

Table 2. Lab values in alphabetical order for all measures with at least $95 \%$ availability among all participants. The columns named below and above represent the percentage of patients deviating from the reference range, which encompasses $95 \%$ of the healthy population. Comparison PS = Comparison of lab-values in the two cohorts: With vs without persistent symptoms.

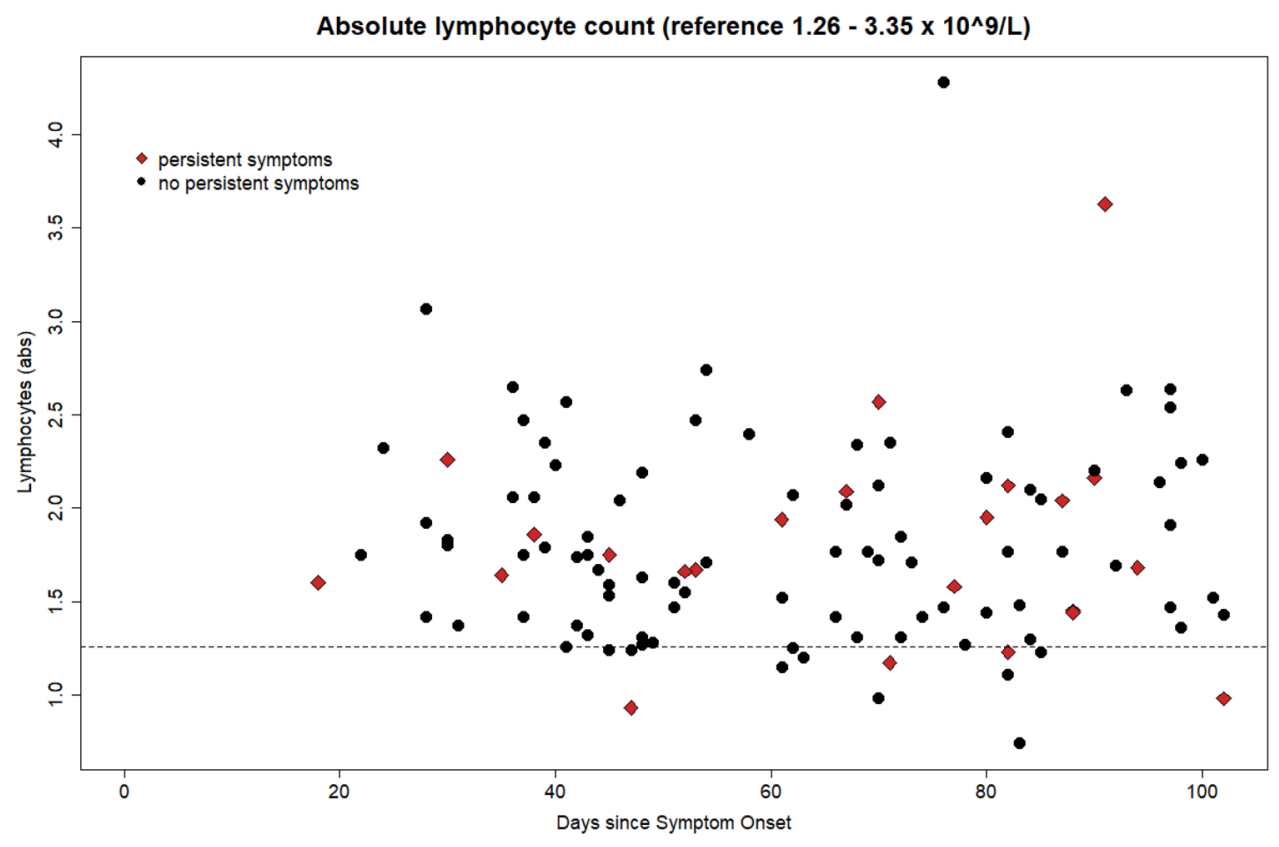

Figure 4. Absolute lymphocyte count over time. Dashed line represents lab-specific lower limit $\left(1.26 \times 10^{9} / \mathrm{L}\right)$.

Regarding duration of persistent symptoms, our results are significantly different: The post-acute setting in Carfi et al. observed $87.2 \%$ of patients having persistent symptom with mean follow-up of around 60 days. Calvao-Schneider et al. $2020^{22}$ reported that $66 \%$ of patients experienced symptoms at day $60^{22}$. The difference should be explained by our comorbidity-free and relatively young population (median age: $41 \mathrm{ys}$ ). Moreover, the majority of the population in Calvao-Schneider et al. had an initial hospitalization rate of $35 \%$ vs. $9 \%$ in our study.

The main strength of our study is the integration of detailed symptoms duration and raw lab-data, which enabled not only assessment of out of range values but also differences within the physiological range. The study results show that some of the infection-related lab values remained out of range during follow-up. In particular, lymphopenia-being frequently discussed as a result of direct or indirect viral interactions with lymphocytes ${ }^{12-14}$-remained in a considerable part of our study population, even beyond 90 days of followup (see Fig. 4). Our subgroup analyses showed that patients with lymphopenia experienced more frequently persistent symptoms. To the best of our knowledge, this is the first COVID-19-related study on the duration of lymphopenia along with other routine lab values going beyond 30 days. Further follow-up studies should assess lymphopenia with additional lab analysis to understand the pathogenetic details of lymphocyte-virus interaction.

There are many drivers being discussed to elucidate on the COVID-19-specific pathogenesis related to lymphopenia. SARS-CoV-2 induced apoptosis in ACE2-receptor expressing lymphocytes was found as one possible mechanism that could lead to lymphopenia in COVID-1924. The COVID-19 associated "cytokine storm" syndrome is considered another possible driver of lymphocyte apoptosis ${ }^{25,26}$. Both mechanisms can possibly lead to rapid reduction of lymphocyte counts during acute infection. In our study we found evidence that lymphopenia persists for weeks after recovery from acute disease. There is rising evidence of bone marrow damage due to SARS-CoV-2 infection of hematopoietic stem cells ${ }^{27}$. For SARS-CoV lymphopenia due to thymus suppression has been proposed ${ }^{28}$. Both bone marrow damage and thymus suppression seem possible mechanisms that may lead to persisting lymphopenia after recovery from disease. A recently published study provided evidence of increased mortality in COVID-19 patients during 6 month after recovery from disease. Besides increased risk of cardiovascular, gastrointestinal and thrombotic complications, rates of infections were found to be significantly 
increased ${ }^{29}$. An association of persistent lymphopenia with increased rates of infections due to a relevant immunosuppressive status is hypothetic and needs further research.

The comparison of patients with vs without persistent symptoms did not show any differences of lab values except for one: serum concentration of total IgA antibodies. In comparison, there were no significant changes regarding total IgG, IgM and all other lab-tests in Table 2. Secretory IgA is an important factor of mucosal immunity for neutralization of toxins and pathogenic microbes ${ }^{30,31}$. While a high level of serum IgA and SARS$\mathrm{CoV}-2$-specific IgA on diagnosis can initially correlate with disease severity ${ }^{32,33}$, our findings suggest that high levels during or after recovery is associated with a decrease in persistent symptoms. In this regard, IgA may play a more important role than other immunoglobulin types. As this study only reports on lab-value correlations, further research can complement our findings regarding causality.

The principal limitation of this study is the retrospective single-center design with symptom assessment not being objective and being prone to recall bias. Moreover, the different follow-up times also lead to different time distances between last day of symptoms and the actual lab-assessment. As some lab-values return to normal levels over a certain time, some lab tests and association with symptom persistence could have faded out and thus failed to show significance in our analysis.

\section{Conclusion}

Our study results could confirm the main persistent symptoms of COVID-19. Lymphopenia persisted in a noticeable percentage of recovered patients beyond 30 days after disease diagnosis. Patients with persistent symptoms had significantly lower serum IgA concentration, which requires further studies to understand detailed pathogenesis.

Received: 4 December 2020; Accepted: 21 May 2021

Published online: 17 June 2021

\section{References}

1. Dong, E., Du, H. \& Gardner, L. An interactive web-based dashboard to track COVID-19 in real time. Lancet. Infect. Dis 20(5), 533-534 (2020).

2. Zhou, F. et al. Clinical course and risk factors for mortality of adult inpatients with COVID-19 in Wuhan, China: a retrospective cohort study. Lancet 28(395), 1054-1062 (2020).

3. Kumar, A. et al. Clinical features of COVID-19 and factors associated with severe clinical course: a systematic review and metaanalysis. SSRN 21, 3566166 (2020).

4. Menter, T. et al. Postmortem examination of COVID-19 patients reveals diffuse alveolar damage with severe capillary congestion and variegated findings in lungs and other organs suggesting vascular dysfunction. Histopathology 77(2), 198-209 (2020).

5. Gupta, A. et al. Extrapulmonary manifestations of COVID-19. Nat. Med. 26(7), 1017-1032 (2020).

6. Wu, Z. \& McGoogan, J. M. Characteristics of and important lessons from the coronavirus disease 2019 (COVID-19) outbreak in china: summary of a report of 72314 cases from the Chinese center for disease control and prevention. JAMA 323(13), 1239-1242 (2020).

7. Li J, Huang DQ, Zou B, Yang H, Hui WZ, Rui F, et al. Epidemiology of COVID-19: A systematic review and meta-analysis of clinical characteristics, risk factors, and outcomes. Journal of Medical Virology [Internet]. [cited 2020 Sep 15];n/a(n/a). Available from: https://onlinelibrary.wiley.com/doi/abs/https://doi.org/10.1002/jmv.26424

8. Li, L. et al. COVID-19 patients' clinical characteristics, discharge rate, and fatality rate of meta-analysis. J. Med. Virol. 92(6), 577-583 (2020).

9. Carfi, A., Bernabei, R. \& Landi, F. Persistent symptoms in patients after acute COVID-19. JAMA 324(6), 603-605 (2020).

10. Struyf, T. et al. Signs and symptoms to determine if a patient presenting in primary care or hospital outpatient settings has COVID19 disease. Cochrane Database Syst. Rev. 7(7), CD013665 (2020).

11. Docherty AB, Harrison EM, Green CA, Hardwick HE, Pius R, Norman L, et al. Features of 20133 UK patients in hospital with covid-19 using the ISARIC WHO Clinical Characterisation Protocol: prospective observational cohort study. BMJ. 2020;369.

12. Terpos, E. et al. Hematological findings and complications of COVID-19. Am. J. Hematol. 95(7), 834-847 (2020).

13. Tan, L. et al. Lymphopenia predicts disease severity of COVID-19: a descriptive and predictive study. Signal Transduct. Target. Ther. 5(1), 1-3 (2020).

14. Zhao, Q. et al. Lymphopenia is associated with severe coronavirus disease 2019 (COVID-19) infections: A systemic review and meta-analysis. Int. J. Infect. Dis. 1(96), 131-135 (2020).

15. Dugas M, Grote-Westrick T, Vollenberg R, Lorentzen E, Brix T, Schmidt H, et al. Less severe course of COVID-19 is associated with elevated levels of antibodies against seasonal human coronaviruses OC43 and HKU1 (HCoV OC43, HCoV HKU1). (2020).https:// doi.org/10.1101/2020.10.12.20211599.

16. iGraph package. https://igraph.org/ [Internet]. [cited 2020 Nov 18]. Available from: https://igraph.org/

17. Sandmann S. Network analysis of onset and persistent symptoms in COVID 19 patients. [Internet]. 2020 [cited 2020 Nov 18]. Available from: https://sand-imi-uni-muenster.shinyapps.io/CovidSymptomNetwork/

18. Common symptoms of ongoing symptomatic COVID-19 and post-COVID-19 syndrome | COVID-19 rapid guideline: managing the long-term effects of COVID-19 | Guidance | NICE [Internet]. NICE; [cited 2021 Apr 18]. Available from: https://www.nice. org.uk/guidance/ng188/chapter/Common-symptoms-of-ongoing-symptomatic-COVID-19-and-post-COVID-19-syndrome

19. CDC. Healthcare Workers [Internet]. Centers for Disease Control and Prevention. 2020 [cited 2021 Apr 18]. Available from: https://www.cdc.gov/coronavirus/2019-ncov/hcp/clinical-care/post-covid-conditions.html

20. Klopfenstein, T. et al. Features of anosmia in COVID-19. Med. Mal. Infect. 50(5), 436-439 (2020).

21. Bilinska K, Butowt R. Anosmia in COVID-19: A Bumpy Road to Establishing a Cellular Mechanism. ACS Chem Neurosci. 11(15), 2152-2155 (2020).

22. Carvalho-Schneider C, Laurent E, Lemaignen A, Beaufils E, Bourbao-Tournois C, Laribi S, et al. Follow-up of adults with noncritical COVID-19 two months after symptoms' onset. Clin Microbiol Infect. (2020).

23. Garrigues E, Janvier P, Kherabi Y, Le Bot A, Hamon A, Gouze H, et al. Post-discharge persistent symptoms and health-related quality of life after hospitalization for COVID-19. J Infect 81(6). (2020)https://www.ncbi.nlm.nih.gov/pmc/articles/PMC7445491/

24. Xiong, Y. et al. Transcriptomic characteristics of bronchoalveolar lavage fluid and peripheral blood mononuclear cells in COVID19 patients. Emerg Microbes Infect. 9(1), 761-770 (2020).

25. Qin, C. et al. Dysregulation of immune response in patients with coronavirus 2019 (COVID-19) in Wuhan China. Clin Infect Dis. 71(15), 762-768 (2020). 
26. Diao, B. et al. Reduction and functional exhaustion of T cells in patients with coronavirus disease 2019 (COVID-19). Front Immunol. 11, 827 (2020).

27. Ratajczak, M. Z. \& Kucia, M. SARS-CoV-2 infection and overactivation of Nlrp3 inflammasome as a trigger of cytokine "storm" and risk factor for damage of hematopoietic stem cells. Leukemia 34(7), 1726-1729 (2020).

28. He, Z. et al. Effects of severe acute respiratory syndrome (SARS) coronavirus infection on peripheral blood lymphocytes and their subsets. Int. J. Infect Dis. 9(6), 323-330 (2005).

29. Al-Aly Z, Xie Y, Bowe B. High-dimensional characterization of post-acute sequalae of COVID-19. Nature. 2021.

30. Renegar, K. B. \& Small, P. A. Passive transfer of local immunity to influenza virus infection by IgA antibody. J. Immunol. 146(6), 1972-1978 (1991).

31. Macpherson, A. J., McCoy, K. D., Johansen, F.-E. \& Brandtzaeg, P. The immune geography of IgA induction and function. Mucosal. Immunol. 1(1), 11-22 (2008)

32. Hasan Ali O, Bomze D, Risch L, Brugger SD, Paprotny M, Weber M, et al. Severe COVID-19 is associated with elevated serum IgA and antiphospholipid IgA-antibodies. Clin Infect Dis [Internet]. [cited 2020 Oct 22]; Available from: https://academic.oup. com/cid/advance-article/doi/https://doi.org/10.1093/cid/ciaal496/5913451

33. Dahlke C, Heidepriem J, Kobbe R, Santer R, Koch T, Fathi A, et al. Distinct early IgA profile may determine severity of COVID-19 symptoms: an immunological case series. medRxiv. 2020 Apr 17;2020.04.14.20059733.

\section{Acknowledgements}

Supported by a grant from BMBF (HiGHmed 01ZZ1802V, Use Case Infection Control).

\section{Author contributions}

JV established the study design, preprocessed the data and wrote the manuscript. SS conducted data analyses. RV, KO, IMS, CF and PRT were involved in data acquisition and preparation. MD, HHS, RV and PRT were involved in the supervision of the project. PRT and RV have jointly supervised the work and contributed equally as cosenior authors. All authors significantly contributed to the manuscript and approved for publication.

\section{Competing interests}

The authors declare no competing interests.

\section{Additional information}

Correspondence and requests for materials should be addressed to J.V.

Reprints and permissions information is available at www.nature.com/reprints.

Publisher's note Springer Nature remains neutral with regard to jurisdictional claims in published maps and institutional affiliations.

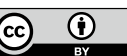

Open Access This article is licensed under a Creative Commons Attribution 4.0 International License, which permits use, sharing, adaptation, distribution and reproduction in any medium or format, as long as you give appropriate credit to the original author(s) and the source, provide a link to the Creative Commons licence, and indicate if changes were made. The images or other third party material in this article are included in the article's Creative Commons licence, unless indicated otherwise in a credit line to the material. If material is not included in the article's Creative Commons licence and your intended use is not permitted by statutory regulation or exceeds the permitted use, you will need to obtain permission directly from the copyright holder. To view a copy of this licence, visit http://creativecommons.org/licenses/by/4.0/.

(C) The Author(s) 2021 